\title{
Can We Assure Quality Without Stifling Innovation?
}

\author{
Linda Miller*
}

\section{ABSTRACT}

The emergence of regenerative medicine raises new questions about the best ways to ensure the safety and efficacy of stem cell therapies for patients. The Foundation for the Accreditation of Cellular Therapy (FACT) believes minimum requirements for cellular therapy for regenerative medicine will promote patient safety, protect the research environment, and aid in the swift advancement of regenerative therapies from bench to bedside. The standards development process has demonstrated that consensus on minimum requirements advances the field. FACT's accreditation process and newly established "Common Standards for Cellular Therapies" can help meet unmet needs in regenerative medicine that will drive commercialization of new cell therapies.

It's been said that regenerative medicine resembles the Wild West. As on all frontiers of medicine, the novel therapies offer hope for previously incurable and even untreatable diseases and injuries. But while some laboratory and clinical investigations have been, to their credit, carefully calibrated and methodical, others are more freelance and freewheeling.

There is, however, a way to stitch together a coherent path for advancing the art and science of regenerative medicine while protecting its integrity. The needle and threads already exist, having evolved in one of the more advanced areas of cellular therapy. And the stitching doesn't require heavy-handed government regulation.

Foundation for the Accreditation of Cellular Therapy, University of Nebraska Medical Center, Omaha, Nebraska.

*(Correspondence: Imiller1@unmc.edu)

\section{A success story}

To present my case, let me give you a brief chronology of a cellular therapy that has been maturing over the past few decades.

- The first successful hematopoietic stem cell transplant was performed in the late 1950 s between two identical twins. The recipient had leukemia.

- The first allogeneic blood transplant between siblings was in the late 1960s.

- The first successful engraftment from an unrelated donor took place in the mid1970s when a young boy in New York, who had a genetic immunodeficiency disorder, received genetically matched cells from a donor identified through a blood bank in Denmark.

Investigations over the next decade advanced to the point at which a federally

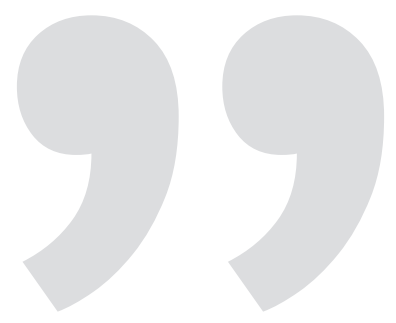

FACT is helping to pilot clinical and laboratory standards in several treatment centers that are pursuing novel cellular therapies.

funded National Marrow Donor Registry was established in 1986.

Also during this period, the pioneers in the field, occasionally and wryly described as cowboys, recognized the significance of what they were doing, but also recognized the problem of insular investigations at multiple research centers. Intent on solving this problem, they created the predecessor to the Center for International Blood and Marrow Transplant Research and voluntarily began contributing their patient and treatment data for study and analysis.

Fast-forward to the early 1990s. The indications for blood and marrow transplant were growing exponentiallywhich naturally attracted the attention of government regulators. Primarily to raise the standards of hematopoietic stem cell transplant, but also to demonstrate that 
intrusive government regulation was not necessary, the blood and marrow transplant community created a nonprofit voluntary organization to create standards and accredit transplant programs. Founded in 1996, the organization became the Foundation for the Accreditation of Cellular Therapy (FACT).

That FACT has been a success is an understatement:

- Today more than $90 \%$ of the blood and marrow transplant centers in the United States are FACT accredited.

- Most all health insurers require FACT accreditation for participation in their centers of excellence.

- FACT's inspectors, who are trained volunteers, evaluate cell collection facilities, processing laboratories, and clinical programs.

- Updates of FACT standards are accomplished in cooperation with a European counterpart organization so that the standards are truly global.

- And, importantly, regulations of transplant that have been enacted by the FDA are largely patterned after FACT standards that were developed by the transplant community.

A key to this success can be found in a "Values Statement" that is part of FACT's strategic plan. It states the transplant community's core belief that "a voluntary organization of practicing professionals is best positioned to improve patient care and foster development of the cell therapy field through quality standards and accreditation."

\section{Success replicated:}

\section{cord blood}

Lest anyone think FACT's success is an aberration, its progression from collaboration to standards to accreditation was duplicated in the umbilical cord banking industry.

The first successful cord blood transplant was in 1988 in France, and the first public cord blood bank in America opened for business in 1992. Leaders in the field created the International NetCord Foundation and joined with FACT to develop global standards and an accreditation program. Today there are more than 50 FACT-NetCord-accredited cord blood banks in 20 countries, and another 20 banks are in various steps of seeking accreditation. The federal government recognizes FACT accreditation for banks participating in its National Cord Blood Inventory.

\section{Act three: cardiology}

Currently, the same pattern is unfolding in the field of regenerative medicine for cardiovascular disease. FACT has initiated a collaboration with the NIH/NHLBI Cardiovascular Cell Therapy Research Network (CCTRN). This collaboration, which includes inspections of cardiovascular cell therapy clinical sites and cell processing facilities across the nation, is helping FACT to develop manufacturing and quality control benchmarks and criteria. If these efforts are fruitful, the next step will be the development of standards that can be the basis of voluntary accreditation.

\section{Universal standards}

The clinical and laboratory standards for blood and marrow transplant, cord blood banking, and cardiovascular therapy have a lot in common. Recognizing this, the FACT Board of Directors appointed a task force to extract those common elements. These have been assembled into "Common Standards for Cellular Therapies," which was published for public comment in April. Later in the year, the task force will finalize the common standards, with the benefit of public feedback.

Once approved by the FACT board, the common standards can serve as a measure of quality and patient safety for investigations and treatment in most any medical discipline or specialty. They also can be the core for any discipline-specific and product-specific standards and accreditation.

\section{Common Standards for Cellular Therapies}

Currently in draft form, the Common Standards for Cellular

Therapies are derived from current editions of FACT-JACIE standards for hematopoietic cellular therapy and NetCord-FACT standards for cord blood banking. They represent the basic fundamentals of cellular therapy that can be applied to any cell source or therapeutic application, and are intended to be used throughout product development and clinical trials. The stated intention of the standards is the promotion of quality medical and laboratory practices in a broad range of cellular therapies. These common standards could also serve as the basis for a new voluntary accreditation in basic cell therapy.

For further information, the draft standards can be viewed at:

factwebsite.org/common standardsmay 2014

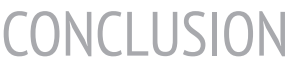

Experience gained from both the hematopoietic stem cell transplant and cord blood banking fields indicates that not only can quality and patient safety be assured through voluntary professional standards, but also that consensus on minimum requirements advances the field. Bringing therapies from the bench to the bedside requires a high level of quality and credibility. FACT's accreditation process and newly established "Common Standards for Cellular Therapies" can help meet unmet needs in regenerative medicine that will drive commercialization of new cell therapies while protecting its integrity and ensuring patient safety.

\section{Author Disclosure}

\section{Statement}

No competing financial interests exist. 